\title{
Old beagle dogs have lower faecal concentrations of some fermentation products and lower peripheral lymphocyte counts than young adult beagles
}

\author{
Márcia de Oliveira Sampaio Gomes ${ }^{1}$, Mariana Casteleti Beraldo ${ }^{1}$, Thaila Cristina Putarov ${ }^{2}$, Márcio \\ Antônio Brunetto ${ }^{1}$, Leandro Zaine ${ }^{1}$, Maria Beatriz Abreu Glória ${ }^{3}$ and Aulus Cavalieri Carciofi ${ }^{1 *}$ \\ ${ }^{1}$ Veterinary Medicine and Surgery Department, College of Agrarian and Veterinarian Sciences (FCAV), São Paulo State \\ University - UNESP, Via de Acesso Prof. Paulo Donato Castellane, s/n. Jaboticabal, SP 14.884-900, Brazil \\ ${ }^{2}$ Faculty of Veterinary Medicine and Animal Science (FMVZ), São Paulo State University, UNESP. Distrito de Rubião Júnior, \\ s/n. Botucatu, SP 18.618-970, Brazil \\ ${ }^{3}$ Pharmacy Faculty, Minas Gerais Federal University (UFMG), Avenida Antonio Carlos, 6627, Belo Horizonte, \\ MG 31.210-901, Brazil
}

(Received 20 October 2010 - Revised 26 April 2011 - Accepted 3 May 2011)

\section{Abstract}

The effects of age on microbiota composition, gut fermentation end-product formation and peripheral lymphocyte numbers were compared between old and young adult Beagle dogs fed four kibble diets differing in yeast cell wall contents. The experiment had a double $4 \times 4$ Latin square design, one with four mature dogs ( 4 years old) and the other with four old dogs (10 years old), with four replicates (diets) per dog. In each period a $15 \mathrm{~d}$ adaptation period preceded a $5 \mathrm{~d}$ total collection of faeces for the digestibility trial. On day 21, fresh faecal samples were collected for the determination of bacterial enumeration, pH, biogenic amine and short-chain fatty acid. Flow cytometry was used for immunophenotypic evaluation. Dogs were fed four kibble diets with similar composition with $0,0 \cdot 15,0.30$ and $0.45 \%$ of yeast cell wall (as-fed), respectively. Data were evaluated using general linear models of Statistical Analysis Systems statistical software $(P<0 \cdot 05)$. No evidence of a difference in faecal bacteria counts between ages was found (total aerobes, total anaerobes, Bifidobacterium, Lactobacillus, Clostridium and Escherichia coli: $P>0 \cdot 15)$. Faecal concentrations of butyrate, histamine, agmatine and spermine were lower $(P \leq 0.05)$ and faecal $\mathrm{pH}$ was higher $(P=0.03)$ in older dogs than in mature adult dogs, suggesting an alteration in bacterial metabolic activity, or in the rate of intestinal absorption of these compounds. Concentrations of T-lymphocytes, T-cytotoxic lymphocytes and B-lymphocytes were also lower $(P \leq 0 \cdot 01)$ in older dogs than in mature adult dogs. The study confirmed alterations in peripheral lymphocytes and revealed a reduced concentration of some fermentation end products in the colon of old dogs.

Key words: Biogenic amines: Butyrate: Digestibility: Microbiota

Gut physiology and function, such as bacterial populations and the formation of fermentation end products, change during ageing but there is conflicting information concerning how gut microbiota change with age in $\operatorname{dogs}^{(1-3)}$. The existing data are conflicting: one study has reported an increase in lactobacilli and bacteroides ${ }^{(4)}$ and another has reported a reduction in bacteroides, bifidobacteria, lactobacilli and anaerobic cocci in old dogs ${ }^{(3)}$. Only one publication evaluating the effect of age on fermentation end-product concentrations has been found. This study has suggested that old dogs have higher butyrate, valerate and isovalerate concentrations in the colon ${ }^{(2)}$.

Age-related changes in systemic immunity include: a decrease in the proliferative response of blood mononuclear cells to mitogens; a decline in the number of peripheral blood lymphocytes, B-cells, T-cells and the relative percentage of $\mathrm{CD} 4+$ (helper) T-cells; an increase in the relative percentage of $\mathrm{CD} 8+$ (natural killer) $\mathrm{T}$-cells resulting in a decreased ratio of $\mathrm{CD} 4+: \mathrm{CD} 8+$ cells $^{(5)}$. These changes also occur within the intestinal 'lamina propria' of ageing dogs with reduced T-cell numbers and lower proliferative activity of intestinal cell populations ${ }^{(5)}$. Considering the linkage between gut function, microbiology and systemic immunity ${ }^{(6)}$, the alterations of gut microbiota and fermentation end products of old dogs may be related to immunological changes. The present study compared diet digestibility, faecal microbiota composition, formation of gut fermentation end products and some immunological parameters of old and mature dogs.

*Corresponding author: A. C. Carciofi, fax +55 16 3203-1226, email aulus.carciofi@gmail.com 


\section{Materials and methods}

The study was conducted at the Laboratory of Research on Nutrition and Nutritional Diseases of Dogs and Cats, UNESP, Jaboticabal, Brazil. All procedures were approved by the Ethics and Animal Welfare Committee (Protocol no. 02468306). The present experiment was originally designed to study the effects of yeast cell wall inclusion in the diet. There was no interaction between age and diet for any variable ( $P$ values varied from $P=0 \cdot 13$ for food metabolisable energy to $P=0.99$ for faecal DM), so we report the effects of age regardless of the diet.

\section{Animals}

The assay was carried out with eight adult clinically healthy Beagles with an average body weight of 11.45 (SEM 2.54) kg. Dogs were separated into two groups; one group had four mature dogs (4 (SEM 0.01) years old) and the second group had four old dogs (10 (SEM 0.02) y-old). The dogs were housed in pairs (one old and one mature) in kennels and allocated randomly to treatments using a double $4 \times 4$ Latin square design structure.

\section{Diets and feeding}

Dietary treatments consisted of four isonutrient kibbled diets prepared using the current guidelines for dogs' maintenance $^{(7)}$. Experimental diets had four inclusion concentrations of yeast cell wall (ActiveMOS ${ }^{\circledR}$; Biorigin, Lençóis Paulista, SP, Brazil) on an as-fed basis: 0, 0.15, 0.30 and 0.45\%. The main ingredients were poultry meal, broken rice, maize and poultry fat. No differences in diet nutrient composition were found (33.3\% crude protein; $15.2 \%$ acid-hydrolysed fat; $2.4 \%$ crude fibre, $7 \cdot 6 \%$ ash and $20.9 \mathrm{~kJ} / \mathrm{g}(5.0 \mathrm{kcal} / \mathrm{g})$ gross energy, on a DM basis). Dogs were initially fed individually calculated amounts $^{(7)}$, divided into two equal meals at 08.00 and 18.00 hours. Food intake was recorded daily, and body weight was recorded weekly. Food amount was adjusted each week to maintain a constant body weight throughout the study. Water was provided ad libitum.

\section{Sample collection and handling}

Each experimental period lasted $21 \mathrm{~d}$. In each period, a $15 \mathrm{~d}$ adaptation preceded a $5 \mathrm{~d}$ total collection of faeces and urine for the digestibility trial. For faecal collection, dogs were kept in individual stainless-steel metabolic cages $(90 \times 90 \times 100 \mathrm{~cm})$. Collected faeces were weighed, pooled by $\operatorname{dog}$ and frozen at $-15^{\circ} \mathrm{C}$. On day 21 , a fresh faecal sample was collected in a sterile container for bacterial enumeration (total anaerobes, total aerobes, Bifidobacterium spp., Lactobacillus spp., Clostridium spp. and Escherichia coli) and within a maximum of $30 \mathrm{~min}$ after defecation, the analysis was initiated. Additional aliquots were collected and used for measurement of fermentation end products (biogenic amines, short-chain fatty acids and lactate) and pH. Faecal samples for short-chain fatty acid and lactic acid analysis were placed immediately into $16 \%(\mathrm{v} / \mathrm{v})$ formic acid aqueous solution (one part of a sample to three parts of a solution). A similar procedure was performed for biogenic amine analysis with samples diluted in 5\% (w/v) trichloroacetic solution (one part of a sample to 1.5 parts of a solution). Samples were diluted in deionised water $(1: 10, \mathrm{w} / \mathrm{v})$ for faecal $\mathrm{pH}$ measurements. A blood sample $(7 \mathrm{ml})$ was also collected on day 21 via jugular puncture into an evacuated tube containing EDTA for complete blood count and immunophenotypic quantification of lymphocyte subsets.

\section{Chemical and microbiological analyses}

Diet and faecal samples were analysed for DM, organic matter, crude protein, ash, crude fibre and hydrolysed fatty acid using standard methods ${ }^{(8)}$. Short-chain fatty acid concentrations were determined by gas chromatography (Finnigan 9001; Finnigan Corporation, Austin, TX, USA) according to Erwin et $a{ }^{(9)}$. Lactate concentrations were measured spectrophotometrically (QUICK-Lab, Drake Eletrônica Comércio Ltda, São José do Rio Preto, SP, Brazil) as described by Pryce ${ }^{(10)}$. Biogenic amine concentrations were determined using HPLC (model LC-10AD; Shimadzu Corporation, Kyoto, Japan) according to Vale \& Gloria $^{(11)}$.

Microbial populations were determined by serial dilution $\left(10^{-1}-10^{-7}\right)$ of faecal samples in peptone water before inoculation onto petri dishes containing sterile agar. For total anaerobe and total aerobe enumeration, diluted samples were grown in plate count agar; E. coli were grown on MacConkey agar; and Lactobacilli were grown on ManRogosa Sharpe agar (all from Acumedia Manufacturers, Inc., Lansing, MI, USA). The selective media for bifidobacteria was bifidobacteria agar (Himedia Laboratories, Mumbai, India). Agar used to grow Clostridium was Reinforced Clostridium Agar (Oxoid Limited, Basingstoke, Hampshire, UK). Samples for total anaerobes, Bifidobacterium, Lactobacillus and Clostridium were incubated anaerobically (73\% N:20\% $\left.\mathrm{CO}_{2}: 7 \% \mathrm{H}_{2}\right)$ at $37^{\circ} \mathrm{C}$. Total aerobes and $E$. coli were incubated aerobically at $37^{\circ} \mathrm{C}$. Plates were counted between 24 and $48 \mathrm{~h}$ after inoculation. Colony-forming units were defined as distinct colonies measuring at least $1 \mathrm{~mm}$ in diameter.

\section{Haematological and immunological analyses}

Complete blood count quantification was performed on an ABC analyser (Horiba ABX Brasil, Jurubatuba, SP, Brazil). To obtain differential leucocyte counts, blood smears were stained with a mixture of May-Grünwald and Giemsa stains in absolute methanol. For the determination of lymphocyte subsets, a two-colour immunofluorescence technique was used. Briefly, $100 \mu$ l of blood were incubated with $2 \mu \mathrm{l}$ of the antibodies (control isotypes y1/PE/R104 and y2/FITC/ MCA1212; CD5/FITC/MCA1037, CD4/PE/MCA1038, CD8/PE/ MCA1039, CD45/FITC/MCA1042F, CD21/PE/ MCA1781; Abd Serotec, Raleigh, NC, USA) at room temperature for $20 \mathrm{~min}$ in the dark. Red blood cells were lysed by adding $2 \mathrm{ml}$ of fluorescence activated cell sorting lysing solution (Becton Dickinson, San Jose, CA, USA) diluted 1:10 in deionised 
Table 1. Faecal $\mathrm{pH}$ and faecal concentration of short-chain fatty acids (SCFA; mmol/ $\mathrm{kg}$ of DM), and biogenic amines $(\mathrm{mg} / 100 \mathrm{~g}$ of faeces) of mature (4 years old) and old (10 years old) Beagle dogs fed with kibble diets

(Mean values with their standard errors, $n 16)^{\star}$

\begin{tabular}{|c|c|c|c|c|}
\hline Item & Mature dogs & Old dogs & SEM & $P$ \\
\hline $\mathrm{pH}$ & $6 \cdot 71$ & $6 \cdot 82$ & 0.03 & 0.03 \\
\hline Faecal DM & $39 \cdot 2$ & $39 \cdot 3$ & 0.3 & 0.77 \\
\hline \multicolumn{5}{|c|}{$(\mathrm{mmol} / \mathrm{kg}$ of faeces in DM) } \\
\hline Acetate & 349.5 & $322 \cdot 0$ & $18 \cdot 0$ & 0.29 \\
\hline Propionate & $136 \cdot 8$ & $132 \cdot 3$ & 7.9 & 0.69 \\
\hline Butyrate & 53.9 & 41.4 & $3 \cdot 2$ & 0.01 \\
\hline Total SCFA & $540 \cdot 3$ & 529.5 & $27 \cdot 1$ & 0.26 \\
\hline Lactate & $33 \cdot 0$ & $33 \cdot 7$ & $2 \cdot 4$ & 0.85 \\
\hline \multicolumn{5}{|c|}{$(\mathrm{mg} / 100 \mathrm{~g}$ of faeces in DM) } \\
\hline Histamine & 0.5 & 0.3 & 0.05 & 0.05 \\
\hline Agmatine & 0.7 & 0.2 & 0.09 & 0.01 \\
\hline Spermine & 31.4 & $17 \cdot 9$ & 3.3 & 0.01 \\
\hline Putrescine & $22 \cdot 9$ & $22 \cdot 9$ & 1.6 & 0.99 \\
\hline Cadaverine & $6 \cdot 0$ & $6 \cdot 3$ & 0.7 & 0.79 \\
\hline Tyramine & $2 \cdot 2$ & $2 \cdot 6$ & 0.3 & 0.42 \\
\hline Spermidine & $17 \cdot 3$ & 14.5 & 4.0 & 0.63 \\
\hline Phenyletilamine & 1.7 & 1.9 & 0.2 & 0.63 \\
\hline Tryptamine & 1.5 & 1.5 & 0.14 & 0.71 \\
\hline Serotonin† & & & - & - \\
\hline Total amines & $83 \cdot 7$ & $67 \cdot 6$ & $7 \cdot 1$ & 0.13 \\
\hline
\end{tabular}

* Results of four diets with different inclusions of yeast cell wall.

† Value below the detection limit $(0.04 \mathrm{mg} / 100 \mathrm{~g})$.

water. The cells were incubated for $10 \mathrm{~min}$ at room temperature in the dark and were then washed three times with $2 \mathrm{ml}$ of $0 \cdot 01 \mathrm{M}-\mathrm{PBS}(\mathrm{pH} 7 \cdot 4-7 \cdot 6$ ) solution, and $0.5 \mathrm{ml}$ of $1 \%$ formalin PBS solution was added. Samples were analysed on a flow cytometer (FACSCanto ${ }^{\circledR}$; Becton Dickinson, San Jose, CA, USA) within $24 \mathrm{~h}$ after staining of the cells. List mode data was acquired for 10000 cells per tube. FACSDiva ${ }^{\circledR}$ software (Becton Dickinson, San Jose, CA, USA) was used for data acquisition and analysis. Results of the flow analysis were computed as the percentage of lymphocytes reacting with the particular antibody. Absolute lymphocyte subset counts were calculated as the product of the absolute lymphocyte count, derived from the haematology analyser, and the percentage of the lymphocyte subpopulations determined by flow cytometry.

\section{Statistical analysis}

Data were analysed by the general linear model procedure of the Statistical Analysis Systems statistical software package version 9.0 (SAS Institute, Cary, NC, USA). The experimental design consisted of two $4 \times 4$ Latin squares, one for mature dogs and the other for old dogs. The statistical model included the effects of animal, period, diet and age group. Results were considered statistically different at $P<0 \cdot 05$. All data were found to comply with ANOVA assumptions. Results are expressed as means with their standard errors.

\section{Results}

Body weight did not change during the trial $(P=0 \cdot 28)$. The old dog group was slightly lighter $(11 \cdot 2$ (SEM $3 \cdot 2) \mathrm{kg}$ ) than mature dog group (11.8 (SEM 0.8) kg; $P=0.02$ ). Body condition score $^{(12)}$ was significantly different between the age groups (old dogs 4.81 (sem 0.65); mature dogs 5.12 (sEm 0.34); $P=0 \cdot 01$ ), although the difference was not very large.

No evidence of differences between age groups in nutrient digestibility and metabolisable energy of the diets was detected (ranging from $P=0.24$ for gross energy to $P=0.89$ for crude protein; data not shown). There was evidence that old dogs required less metabolisable energy to maintain a constant body weight during the 3-month period of the trial (mature dogs consumed 544 (SEM 45) kJ (130 (SEM 46) kJ (11 kcal)) $/ \mathrm{kg}^{0.75} / \mathrm{d}$; old dogs 461 (SEM 114) kJ (110 (sEM $\left.113) \mathrm{kJ}(27 \mathrm{kcal})) / \mathrm{kg}^{0.75} / \mathrm{d} ; P<0.001\right)$, reflecting the reduced energy requirement of these animals. Diet consumption was good, with no episodes of diarrhoea, vomiting or refusal to feed during any experiment.

There was no evidence of an age effect on microbial faecal counts (log of colony-forming units/g of faecal DM; $P>0 \cdot 15$ ), with similar numbers of total aerobes (16.1 (SEM 1.5)), total anaerobes (16.3 (SEM 1.5)), E. coli (14.2 (SEM 1.0)), Clostridium spp. (9.1 (SEM 1.1)), Lactobacillus spp. (15.5 (SEM 1.9)), and Bifidobacterium spp. (16.5 (SEm 1.6)). There was, however, evidence of differences between ages in the concentration of some bacterial end products. Faecal concentrations of butyrate, histamine, agmatine, and spermine were lower $(P \leq 0.05)$ and faecal $\mathrm{pH}$ was higher $(P=0.03)$ in older dogs than in mature adult dogs, as shown in Table 1.

No evidence of a difference in erythrocyte concentration between the groups was detected $(P=0 \cdot 11)$, but old dogs showed evidence of a lower concentration of leucocytes $\left(6.6 \times 10^{3}\right.$ cells $\left./ \mu \mathrm{l}\right)$ than mature animals $\left(10 \times 10^{3} \mathrm{cells} / \mu \mathrm{l}\right.$; $P<0 \cdot 01)$. However, all values remained within the reference interval of the laboratory. Concentration of T-lymphocytes $\left(\mathrm{CD}^{+}\right)$, T-cytotoxic lymphocytes $\left(\mathrm{CD}^{+} \mathrm{CD}^{+}\right)$and $\mathrm{B}-$ lymphocytes $\left(\mathrm{CD} 45^{+} \mathrm{CD} 21^{+}\right)$were lower $(P \leq 0 \cdot 01)$ in older dogs than in mature adult dogs (Table 2).

Table 2. Lymphocyte subset concentrations (cells/ $\mu \mathrm{l}$ ) in the peripheral blood of mature (4 years old) and old (10 years old) Beagle dogs fed with kibble diets (Mean values with their standard errors, $n 16)^{*}$

\begin{tabular}{lccrr}
\hline Items & Mature dogs & Old dogs & SEM & $P$ \\
\hline T-lymphocytes $\left(\mathrm{CD5}^{+}\right)$ & 845 & 609 & 35.5 & 0.02 \\
T-helper lymphocytes $\left(\mathrm{CD5}^{+} \mathrm{CD}^{+}\right)$ & 396 & 389 & 41.1 & 0.90 \\
T-cytotoxic lymphocytes $\left(\mathrm{CD5}^{+} \mathrm{CD}^{+}\right)$ & 188 & 117 & 14.2 & $<0.01$ \\
Leucocytes $\left(\mathrm{CD} 45^{+}\right)$ & 973 & 599 & 84.2 & $<0.01$ \\
B-lymphocytes $\left(\mathrm{CD} 45^{+} \mathrm{CD} 21^{+}\right)$ & 184 & 83 & 26.7 & 0.01 \\
\hline
\end{tabular}

* Results of four diets with different inclusions of yeast cell wall. 


\section{Discussion}

These results support previous studies ${ }^{(13)}$ and confirm no effect of age on the apparent digestibility of nutrients. Although an age effect on faecal bacterial counts was expected, none was observed. Benno et al. ${ }^{(3)}$ have shown that lactobacilli, Bacteroides, peptostreptococci, and bifidobacteria were lower, whereas lecithinase-positive clostridia and bacilli numbers were elevated in faeces of older dogs. Another study has reported that Bacteroides spp. increased $31 \%$ in old dogs ${ }^{(4)}$. Thus, there is no consensus concerning the effect of age on faecal bacterial counts.

Although modest, the lower concentrations of fermentation end products in the faeces (higher $\mathrm{pH}$, and lower butyrate and biogenic amines) of old dogs were in contrast to the only other published study in this topic, which observed higher butyrate, valerate and isovalerate concentrations in the colon of old animals ${ }^{(2)}$. Kuzmuk et al. ${ }^{(2)}$ attributed their results to changes that occur with age in colonic microbial composition or in host absorptive capacity of amino acids in the small intestine, which would cause a larger amount of substrate to enter the colon for microbial degradation. In the present and other studies $^{(13)}$, total gut protein digestibility was not influenced by age, making the hypothesis of higher amounts of substrate for colonic fermentation less likely unless colonic fermentation masked changes in absorption within the small intestine. No other study considering the effect of age on faecal concentration of biogenic amines in dogs was found.

The reduced concentration of fermentation end products in old dogs in the present study could have at least three main explanations: reduced microbial production, higher gut absorption of these compounds or less substrate available in the colon of these animals due the reduced food intake. Possibly, even if bacterial counts were not changed, their metabolic activity could be modified by changes in the colon environment of ageing dogs. It is important to note that not all compounds exhibited reduction (e.g. acetate and propionate). The possible implications of these findings are largely dependent on their causative factors.

The presented data indicated an age-related decrease in the concentration of T-cells, CD8 T-cells and B-cells, in agreement with previous publications ${ }^{(5)}$. These immunological alterations may contribute to morbidity and mortality in ageing individuals ${ }^{(5)}$. Among the many factors that could contribute to immunosenescence, the participation of the gut environment has been little explored in dogs and should be considered.

\section{Conclusion}

Data presented here suggest an age-related decline for some immune parameters, confirming immunological alterations in old dogs, and revealed a reduced concentration in some fermentation products in the faeces of old dogs.

\section{Acknowledgements}

M. d. O. S. G. and A. C. C. conceived the present study and drafted the manuscript. M. B. A. G. performed the biogenic amines analyses. M. d. O. S. G. was the main executer, and T. C. P., M. A. B., M. C. B. and L. Z. contributed to the execution of the research. All of the authors contributed to the critical revision of the manuscript. The study was supported by Mogiana Alimentos (Guabi), Campinas, Brazil and Biorigin, Lençóis Paulista, SP, Brazil. None of the authors has any conflicts of interest.

\section{References}

1. Teshima E, Brunetto MA, Vasconcellos RS, et al. (2010) Nutrient digestibility, but not mineral absorption is agedependent in cats. J Anim Physiol Anim Nutr 94, e251-e258.

2. Kuzmuk KN, Swanson KS, Tappenden KA, et al. (2005) Diet and age affect intestinal morphology and large bowel fermentative end-product concentrations in senior and young adult dogs. J Nutr 135, 1940-1945.

3. Benno Y, Nakao H, Uchida K, et al. (1992) Impact of the advances in age on the gastrointestinal microflora of Beagle dogs. J Vet Med Sci 54, 703-706.

4. Kearns RJ, Hayek MG \& Sunvold GD (1998) Microbial changes in aged dogs. In Recent Advances in Canine and Feline Nutrition, vol. II, pp. 337-351 [GA Reinhart and DP Carey, editors]. Wilmington, OH: Orange Frazier.

5. Day MJ (2010) Ageing, immunosenescence and inflammageing in the dog and cat. J Comp Path 142, S60-S69.

6. Topping DL \& Clifton PM (2001) Short-chain fatty acids and human colonic function: roles of resistant starch and nonstarch polysaccharides. Physiol Rev 81, 1031-1064.

7. National Research Council (US) Ad hoc Committee on Dog and Cat Nutrition (2006) Nutrient Requirements of Dogs and Cats. Washington, DC: The National Academies Press.

8. Association of Official Analytical Chemists (1995) Official Methods of Analysis, 16th ed. Washington, DC: AOAC.

9. Erwin ES, Marco GJ \& Emery EM (1961) Volatile fatty acid analyses of blood and rumen fluid by gas chromatography. J Dairy Sci 44, 1768-1771.

10. Pryce JD (1969) A modification of the Barker-Summerson method for the determination of lactic acid. The Analist 94, 1121-1151.

11. Vale SR \& Gloria MB (1997) Determination of biogenic amines in cheese. J AOAC Int 80, 1006-1012.

12. Laflamme D (1997) Development and validation of a body condition score system for dogs. Canine Pract 22, 10-15.

13. Harper EJ (1998) Changing perspectives on aging and energy requirements: aging and digestive function in humans, dogs and cats. J Nutr 128, 2632S-2635S. 